УдК 796.422.14

ISSN (Ukrainian ed. Print) 1991-0177 ISSN (Ukrainian ed. Online) 1999-818X 2021, № 2(82), C.5-10 doi:10.15391/snsv.2021-2.001

\title{
Характеристики бігу з аудіостимуляцією спортсменів із вадами зору
}

\author{
Андрій Єфременко \\ Святослав Коваль \\ Віктор Павленко \\ Тетяна Шутєєва \\ Ярослав Крайник \\ Світлана Пятисоцька
}

Харківська державна академія фізичної культури, Харків, Україна

Мета: виявити відмінності в бігових характеристиках спортсменів із вадами зору без і зі звуковою стимуляцією.

Матеріал і методи: аналіз, синтез та узагальнення; тестування. Учасники: спортсмени з вадами зору (категорія T13) (хлопці $n=6$ та дівчата $n=5)$. Втручання: тест №1: біг протягом 4 хвилин з поступовим збільшенням темпу; тест №2: біг протягом 4 хвилин у темпі метроному (140; 150; 160; 170 ударів за хвилину).

Результати: порівняння результатів тесту №1 та №2 угрупі юнаків виявило достовірність відмінностей $(p<0,05)$ для: першої та четвертої хвилин бігу; середньої швидкості бігу на другій хвилині. Порівняння результатів тестів №1 та №2 у групі дівчат виявило достовірність відмінностей $(p<0,05)$ для: дистанції бігу в першу хвилину; середньої швидкості бігу на першій та другій хвилинах.

Висновки: визначено особливості реакції спортсменів з вадами зору на біг з аудіостимуляцією. Фізіологічні реакції, які були зареєстровані у хлопців та дівчат були схожими. У той же час існують певні відмінності в стратегії руху учасників дослідження. Це підтверджує комплексний вплив нав'язаного ритму на продуктивність циклічного руху. Ми очікували значних відмінностей між біговими характеристиками із слуховою стимуляцією та без неї. Однак великої кількості достовірних відмінностей між результатами, в тому числі для хлопців і дівчат, не зареєстровано. Виявлено комплексний вплив обраного ритму на результативність бігу спортсменів з порушенням зору. Зафіксовані реакції пов'язані з нозологічними особливостями учасників дослідження. Проте, необхідне проведення більш глибоких досліджень. На цьому етапі ми схильні думати, що обрані частоти метроному зручні для роботи з навантаженням, що зростає східчасто.

Ключові слова: метроном, ритм, темп, легка атлетика.

\section{Вступ}

Людський організм здатний сприймати і реагувати на стимуляцію основних органів чуття ззовні [3]. Індивід здатний довільно обирати конкретний (з різним ступенем усвідомленості) ритм рухової активності. Очевидно, що для ефективного вирішення конкретного рухового завдання ритм буде різним. Наприклад, циклічне пересування (ходьба, біг тощо), які є простими для здорової людини щодня. Вони мають важливе практичне значення для руху, розвитку та контролю підготовленості та реабілітації. Можна сказати, що ритмічні показники циклічного руху вказують на їх якість (економічність та ефективність). В зоні бімануальної координації виділяють ритмо-слухову стимуляцію, яка може стабілізувати внутрішню координацію, створюючи ефект, який називається «закріплення». Коли певна точка циклу руху (наприклад, постановка ноги на опору) синхронізується з метрономом, може виникнути ефект, який називається «закріпленням» [4]. Це дозволяє фіксувати більш стабільний зв'язок між характеристиками опорно-рухового апарату та системи дихання під час циклічних рухів через руховий дихальний зв'язок.
Ритмічні рухові дії можна поєднувати із зовнішніми звуковими подразниками (метрономом та музикою). Це явище відоме як «сенсомоторна синхронізація». У той же час концентрація на зовнішньому подразнику відволікає від внутрішніх переживань (невизначеність, втома, лінь). Показане збільшення часу до втоми внаслідок використання звукових подразників під час фізичних вправ. Передбачається, що це пов'язано з паралельною обробкою зовнішніх та внутрішніх сигналів [1]. Тобто основна увага при виконанні фізичної праці переноситься на зовнішні подразники, спрямовуючись для зменшення сприйняття сигналів про напруження опорно-рухового апарату та серцево-дихальної системи. Також це може бути пов'язано з підвищеним рівнем розслабленості в результаті точного очікування майбутнього руху. Можливо, існує певний «ритмічний малюнок» як найефективніша стратегія вирішення рухового завдання. Частота циклічного руху у бігунів становить від 130 до 200 кроків на хвилину. Втім, можливо, слід говорити лише про індивідуальний ритм руху. У фізичних вправах найчастіше використовується слухова або зорова стимуляція. 
Таким чином, метою дослідження було виявити відмінності в бігових характеристиках спортсменів із вадами зору без і зі звуковою стимуляцією.

\section{Матеріал і методи дослідження}

Учасники: спортсмени з вадами зору (категорія Т13) (хлопці $\mathrm{n}=6$ та дівчата $\mathrm{n}=5$ ).

Етична заява. Дослідження було схвалено Комітетом з етики Харківської державної академії фізичної культури, і всі подальші процедури відповідали Гельсінській декларації. Для визначення класифікації спортсмена використовувався Діагностичний сертифікат, підписаний лікуючим лікарем. Це було достатнім свідченням порушення зору. Спортсмени дали письмову згоду на присвоєння класифікації.

Тест №1. Групи спортсменів із вадами зору (дівчата чи хлопці) за командою «Вперед!» виконували біг протягом 1 хв. у вільному ритмі, який учасник повинен був самостійно підвищувати щохвилини (всього 4 м). Орієнтиром була середня частота серцевих скорочень (ЧСС) та середня швидкість бігу (Ш.б. №... хв; м/с), про які повідомляли учаснику в кінці кожної хвилини. Кожну наступну хвилину рекомендувалось бігати з підвищеним ритмом на основі відчуття власної швидкості бігу та фізіологічних відчуттів. Біг виконувався на майданчику з ґрунтовим покриттям, на ділянці 20 м з яскравою розміткою на кожен метр, яка була обмежена конусами. Коли спортсмен дійшов до конуса, тренер дав команду повернутись і продовжувати бігти в інший бік. Наприкінці 1, 2, 3 хв реєстрували ЧСС (уд/хв), подолану відстань (Дис. №... хв; м) та рейтинг сприйнятого навантаження (RPE №... хв; оцінка) за Боргом «6-20» (від 6 - «Легко» до 20 - «максимальне зусилля»). Після цього учасник повертався до одного з конусів для початку наступної хвилини бігу (загалом $15 \pm 5$ с використовували для запису та повідомлення показників). Як тільки всі учасники тесту були готові, подавався сигнал, щоб почати біг. По закінченні 4 хвилин або у разі відмови продовжувати, ЧСС та Дис. реєстрували після 4 хв. Повідомляли про зміни показників лише для вибору швидкості бігу.

Через дві години учасники виконували Тест №2.

Тест №2. Групи спортсменів (групи по 5 осіб) за командою «Вперед!» виконували біг протягом 1 хв. (загалом 4 хв.) відповідно до ритму метронома, який зростав щохвилини (140, 150, 160, 170 уд/хв). Біг проводився на тій же ділянці, що і в Тесті № 1. Цифровий сигнал метронома подавався через портативну аудіосистему. По закінченні 1, 2, 3 хв. фіксували ЧСС, Дист., і RPE. Наприкінці кожної хвилини учасник повертався до одного з конусів, щоб розпочати наступну хвилину бігу (загалом для запису показників використовували $15 \pm 5$ c). Як тільки всі учасники випробування були готові, був поданий сигнал розпочати біг у заданому ритмі. Фіксували ЧСС, Дист. через 1-4 хв: в кінці 4 м; у разі відмови продовжувати біг; у випадку явної невідповідності заданому ритму бігу (> 15 SPM).

Статистика. Статистичний аналіз проводили за допомогою програмного пакету Statistica 10 (США). Аналіз відповідності вибіркових даних нормальному закону розподілу проводили за допомогою критерію Колмогорова-Смірнова. Параметричні та непараметричні методи аналізу використовувались для опису, оцінки взаємозв'язків та відмінностей у результатах: дескрип- тивна статистика; Коефіцієнт кореляції Пірсона; U-тест Манна-Уітні; t-test - парні зразки. Для всіх аналізів рівень статистичної значущості був встановлений на рівні $\mathrm{p}<0,05$.

\section{Результати дослідження}

Усі учасники мали змогу пройти тест №1 та №2. Виміряні бігові характеристики та ЧСС мали різне наближення до нормального закону розподілу. На основі результатів тесту Колмогорова-Смірнова було обрано відповідний статистичний критерій для порівняння результатів. Кінематичні характеристики та фізіологічні реакції, записані під час бігу без звукової стимуляції, представлені у таблиці 1.

Коефіцієнт варіації ЧСС у групі юнаків за 4 хвилини бігу зменшився (CV $=13,96 ; 10,62 ; 7,51 ; 7,53)$, а в групі дівчат він змінився хвиле подібно (CV = 11,59; 9,26; $10,09 ; 11,59)$. Групова зміна дистанції бігу у групі юнаків зменшилася на третій та четвертій хвилині та збільшилася на другій хвилині тесту (CV = 13,97; 24,07; 17,10; $10,66)$, тоді як у групі дівчат він збільшився (CV = 5,90; $8,67 ; 12,12 ; 12,40)$.

Середня швидкість бігу мала подібну динаміку, як і дистанція бігу учасників обох груп. Коефіцієнт варіації для RPE знизився (CV хлопці: 15,76; 13,53; 14,99; 6,86; CV дівчата: 40,67; 11,61; 11,29; 4,76).

Коефіцієнт варіації частоти серцевих скорочень у групах зменшився (CV хлопці: 15.10; 10.99; 9.57; 7.57; 7.39; CV дівчата: 13.42; 11.94; 11.62; 7.32). Групова варіація бігу на відстань у тестових групах динамічно змінювалася (CV хлопці: 16,05; 22,72; 16,85; 3,54; CV дівчата: 14,74; $15,42 ; 5,58 ; 17,93)$. Середня швидкість бігу учасників обох груп мала однакову динаміку, як і дистанція бігу. Коефіцієнт варіації для RPE зменшився (CV хлопці: 14,50; 20,03; 11,95; 6,00; CV дівчата: 18,49; 21,83; 8,02; 6,61).

Порівняння результатів Тесту №1 між групами виявило достовірність відмінностей $(p<0,05)$ для: ЧСС у першу хвилину бігу; дистанції бігу на другій та четвертій хвилинах.

Порівняння результатів Тесту №2 між групами виявило достовірність відмінностей $(p<0,05)$ для: ЧСС на першій хвилині бігу; дистанція бігу на першій, другій та четвертій хвилинах; середня швидкість бігу на третій хвилині.

Розрахунок кореляційного співвідношення між подібними характеристиками бігу, що виконувався із звуковою стимуляцією та без неї. У групі юнаків виявлено значну кореляцію: ЧСС на першій $(r=0,79)$, другій $(r=0,96)$, третій $(r=0,80)$ і четвертій $(r=0,41)$ хвилинах бігу; дистанція бігу на другій $(r=0,84)$ і третій $(r=0,88)$ хвилинах. У групі дівчат знайдено значну кореляцію: ЧСС на першій $(r$ $=0,56)$, другій $(r=0,59)$ та третій $(r=0,77)$ хвилинах бігу; дистанція бігу на четвертій $(r=0,58)$ хвилині. За всіма іншими показниками суттєвих кореляцій не виявлено.

\section{Висновки / Дискусія}

У нашому дослідженні метроном використовувався в якості слухової стимуляції. Вибираючи ритми для бігу, ми керувалися даними попередніх досліджень. J. Edworthy \& H. Waring (2006) запропонували для бігу музику 70 або 200 уд/хв [2]. К. Karageorghis та ін. (2012) досліджували ходьбу зі швидкістю 80, 120 та 140 ударів на хвилину [5]. F. Styns та ін. (2007) стверджують, що 
Таблиця 1

Результати тестування

\begin{tabular}{|c|c|c|c|c|}
\hline \multirow{3}{*}{ Вимірювання } & \multicolumn{2}{|c|}{ хлопці } & \multicolumn{2}{|c|}{ дівчата } \\
\hline & \multicolumn{4}{|c|}{$\mathrm{M} \pm \mathrm{SD}$} \\
\hline & стимуляція & без стимуляції & стимуляція & без стимуляції \\
\hline ЧСС початок, уд/хв & $105,00 \pm 12,73$ & $97,46 \pm 16,33$ & $102,86 \pm 8,10$ & $100,29 \pm 11,39$ \\
\hline ЧСС №1 хв., уд/хв & $131,46 \pm 18,35$ & $129,81 \pm 19,60$ & $151,86 \pm 17,60$ & $149,29 \pm 20,04$ \\
\hline ЧСС №2 хв., Уд/хв & $155,69 \pm 16,53$ & $154,62 \pm 17,00$ & $165,86 \pm 15,36$ & $164,57 \pm 19,65$ \\
\hline ЧСС №3 хв., Уд/хв & $166,00 \pm 12,47$ & $169,15 \pm 16,19$ & $171,36 \pm 17,28$ & $170,86 \pm 19,86$ \\
\hline ЧСС №4 хв., Уд/хв & $173,42 \pm 13,06$ & $176,46 \pm 13,35$ & $173,71 \pm 20,14$ & $177,43 \pm 13,00$ \\
\hline Дис. №1 хв., м & $118,43 \pm 16,54 *$ & $108,62 \pm 17,43^{*}$ & $91,98 \pm 5,43 *$ & $102,46 \pm 15,10^{*}$ \\
\hline Дис. №2 хв., м & $129,17 \pm 31,08$ & $136,28 \pm 30,97$ & $95,63 \pm 8,30$ & $101,09 \pm 15,59$ \\
\hline Дис. №3 хв., м & $142,70 \pm 24,40$ & $144,66 \pm 24,38$ & $142,07 \pm 17,22$ & $147,53 \pm 8,24$ \\
\hline Дис. №4 хв., м & $136,15 \pm 16,89^{*}$ & $148,44 \pm 5,26^{*}$ & $121,37 \pm 12,94$ & $129,95 \pm 23,31$ \\
\hline Ш.б. №1 хв., $м \cdot c^{-1}$ & $1,97 \pm 0,27$ & $1,81 \pm 0,29$ & $1,53 \pm 0,09 *$ & $1,71 \pm 0,26^{*}$ \\
\hline Ш.б. №2 хв., м·c ${ }^{-1}$ & $2,15 \pm 0,52 *$ & $2,27 \pm 0,52 *$ & $1,60 \pm 0,14^{*}$ & $1,68 \pm 0,0,26^{*}$ \\
\hline Ш.б. №3 хв., м·c ${ }^{-1}$ & $2,38 \pm 0,41$ & $2,41 \pm 0,41$ & $2,37 \pm 0,29$ & $2,46 \pm 0,14$ \\
\hline Ш.б. №4 хв., м·c ${ }^{-1}$ & $2,27 \pm 0,28$ & $2,47 \pm 0,09$ & $2,02 \pm 0,21$ & $2,17 \pm 0,39$ \\
\hline RPE №1 хв., бал & $9,54 \pm 1,50$ & $9,35 \pm 1,35$ & $9,07 \pm 3,69$ & $9,00 \pm 1,66$ \\
\hline RPE №2 хв., бал & $9,81 \pm 1,33$ & $10,12 \pm 2,03$ & $10,93 \pm 1,27$ & $10,14 \pm 2,21$ \\
\hline RPE №3 хв., бал & $13,62 \pm 2,04$ & $13,42 \pm 1,60$ & $14,93 \pm 1,69$ & $14,36 \pm 1,15$ \\
\hline RPE №4 хв., бал & $15,92 \pm 1,09$ & $16,38 \pm 0,98$ & $15,64 \pm 0,74$ & $16,36 \pm 1,08$ \\
\hline
\end{tabular}

* Суттєві відмінності зі слуховою стимуляцією та без слухової стимуляції <0,05

люди можуть синхронізувати музичні ритми в діапазоні 50-190 ударів на хвилину [10]. Ми вибрали ряд ритмів: перехід від швидкої ходьби до бігу (140 уд/хв) до зручної та ефективної каденції бігу (170 уд/хв). Також взяли за основу твердження, що перехід від ходьби до бігу у людини зазвичай відбувається зі швидкістю близько 2,1 м/с [9], що відповідає середній швидкості руху, зафіксованій у нашому дослідженні.

Ми виявили суперечливе зменшення частоти кроку через відставання, що узгоджується із зафіксованими змінами в інших дослідженнях [4, 5]. У свою чергу, Н. Kyrцlдinen та співавт. (2000) \& N. Place та ін. (2004) спостерігали збільшення частоти кроків $[6,8]$.

Частота серцевих скорочень збільшувалась кожну наступну хвилину в Тестах №1 та №2 у спортсменів із вадами зору обох груп. Різниця у фізіологічній реакції полягала лише у збільшенні варіацій у групі дівчат на останній хвилині бігу з аудіостимуляцією. Очевидно, що обидва варіанти тесту не викликали труднощів у спортсменів із вадами зору [10]. Більшості спортсменів із вадами зору вдалося поступово дозувати навантаження і досягати високих значень чСС. Зменшення довжини дистанції на четвертій хвилині учасників обох груп свідчить про вичерпний характер тестів. Збільшення дистанції бігу в групі юнаків на четвертій хвилині бігу без звукової стимуляції можна пояснити мотиваційним фактором і більшою витривалістю, на відміну від дівчат. Однак це суперечить припущенню, що ритм, який синхронізується з темпом роботи особистості, може сприяти збільшенню витривалості при виконанні вправ [10]. Від- сутність істотних відмінностей в динаміці фізіологічних реакцій свідчить про подібність завдання тестування для дотримання ритму або поступового самостійного збільшення швидкості бігу. Учасники обох статей продемонстрували здатність мобілізуватися в процесі вирішення рухового завдання незалежно від способу стимуляції. Це підтверджує здатність тренованих людей оцінювати та дозувати обсяг вправ. Обрана частота може служити вичерпним стимулом для навантаження представленого контингенту учасників дослідження.

Істотних відмінностей для тестових груп між Тестами №1 та №2 щодо RPE не виявлено. Коефіцієнт варіації зменшувався для двох тестів в обох групах. Це підтверджує здатність підготовлених осіб якісно оцінювати та дозувати сприйняті навантаження при вирішенні рухового завдання, незалежно від методу стимуляції [7]. Таким чином, обидва тести були досить виснажливими для учасників обох груп, на що вказують високі показники RPE в кінці тесту та зменшення варіації оцінки в середині груп. Наші дані суперечать тому факту, що дисоціація, спричинена зосередженням на слуховому подразнику, може змінити сприйняття зусиль, що дозволяє бігунам довше працювати більш інтенсивно [7]. Можливо, з іншим характером стимулювання (мотиваційна музика) ми зафіксували б інші результати.

Результати дослідження підтверджують заявлені раніше різними авторами дані про вплив темпу музики на виконання циклічних вправ [7]. Регулювання темпу бігу щодо каденції учасників створило оптимальні умови для сенсомоторної синхронізації в цілому. Це узгоджуєть- 
ся з результатами дослідження М. Roerdink та співавт. (2011) для циклічного руху [9].

Отже, у хлопців та дівчат зафіксовано подібні фізіологічні реакції зареєстровано під час бігу, темп якого збільшувався східчасто, незалежно від методу стимуляції. У той же час існують певні відмінності в стратегії руху залежно від способу стимулювання. Це підтверджує комплексний вплив нав'язаного ритму на продуктивність циклічного руху. Ми очікували суттєвих відмін- ностей між біговими характеристиками з і без слухової стимуляції. Однак великої кількості достовірних відмінностей між результатами тестування не виявлено, що може бути пов'язано з індивідуальними особливостями учасників.

Перспективи подальших досліджень. Розроблені підходи будуть апробовані для інших видів рухової активності в групах студентів, які займаються різними видами спорту.

\begin{abstract}
Конфлікт інтересів. Автори заявляють, що відсутній конфлікт інтересів, який може сприйматись таким, що може завдати шкоди неупередженості статті.

Джерела фінансування. Ця стаття не отримала фінансової підтримки від державної, громадської або комерційної організації.

Подяки. Дослідження проведилося відповідно до ініціативної теми кафедри легкої атлетики ХДАФК «Особливості часо-просторових характеристик спортивної (легка атлетика) та повсякденної рухової діяльності» (державний реєстраційний номер: 0119U103785). Ми вдячні учасникам дослідження за розуміння, бажання взяти участь у дослідженні.
\end{abstract}

\title{
Список посилань
}

1. Рядова, Л., Шестерова, Л. (2018), «Вікова динаміка рівня розвитку статичної рівноваги в учнів середніх класів з вадами зору», Слобожанський науково-спортивний вісник. № 3(65). 52-56.

2. Bacon, C. J., Myers, T. R., Karageorghis, C. I. (2012), «Effect of music-movement synchrony on exercise oxygen consumption», J. Sports Med. Phys. Fitness. №52. 359-365.

3. Edworthy, J., Waring H. (2006), «The effects of music tempo and loudness level on treadmill exercise», Ergonomics. №49. $1597-1610$.

4. Hoffmann, C. P., Torregrosa, G., Bardy, B. G. (2012), «Sound Stabilizes Locomotor-Respiratory Coupling and Reduces Energy Cost», PloS one 7 (9). URL: https://doi.org/10.1371/journal.pone.0045206

5. Hove, M. J., Risen J. L. (2009), «It's all in the timing: Interpersonal synchrony increases affiliation», Soc. Cogn. №27. 949-961.

6. Karageorghis, C. I., Terry, P. C., Lane, A. M., Bishop, D. T., Priest, D. L. (2012), «The BASES expert statement on use of music in exercise», J. Sports Sci. №30. 953-956.

7. Kyrulginen, H., Pullinen, T., Candau, R., Avela, J., Huttunen, P., Komi, P. V. (2000), «Effects of marathon running on running economy and kinematics», Eur. J. Appl. Physiol. №82. 297-304.

8. Mendonзa, C., Oliveira, M., Fontes, L., Santos, J. (2014), «The effect of instruction to synchronize over step frequency while walking with auditory cues on a treadmill», Hum Mov Sci. №33. 33-42.

9. Place, N., Lepers, R., Deley, G., Millet, G. Y. (2004), «Time course of neuromuscular alterations during a prolonged running exercise», Med. Sci. Sports Exerc. №36. 1347-1356.

10. Roerdink, M., Ridderikhoff, A., Peper, C. E., Beek, P. J. (2013), «Informational and neuromuscular contributions to anchoring in rhythmic wrist cycling", Ann Biomed Eng. №41. 1726-39.

Стаття надійшла до редакції: 05.03.2021 р.

Опубліковано: 26.04.2021 р.

\begin{abstract}
Аннотация. Андрей Ефременко, Святослав Коваль, Виктор Павленко, Татьяна Шутеева, Ярослав Крайник, Светлана Пятисоцкая. Характеристики бега с аудиостимуляцией спортсменов с нарушениями зрения. Цель: выявить различия в беговых характеристиках спортсменов с нарушениями зрения без и со звуковой стимуляцией. Материал и методы: анализ, синтез и обобщение; тестирование. Участники: спортсмены с нарушениями зрения (категория Т13) (мальчики $n=6$ и девушки $n=5)$. Вмешательство: тест №1: бег в течении 4 минут с постепенным увеличением темпа; тест №2: бег в течении 4 минут в темпе метронома (140; 150; 160; 170 ударов в минуту). Результаты: сравнение результатов теста №1 и №2 в группе юношей выявило достоверность различий $(p<0,05)$ для: первой и четвертой минут бега; средней скорости бега на второй минуте. Сравнение результатов тестов №1 и №2 в группе девушек выявило достоверность различий $(p<0,05)$ для: дистанции бега на первой минуте; средней скорости бега на первой и второй минутах. Выводы: определены особенности реакции спортсменов с нарушениями зрения на бег с аудиостимуляцией. Физиологические реакции, которые были зарегистрированы у юношей и девушек были схожими. В то же время существуют определенные различия в стратегии передвижения участников исследования. Это подтверждает комплексное воздействие навязанного ритма на производительность циклического упражнения. Мы ожидали значительных различий между беговыми характеристиками со слуховой стимуляцией и без нее. Однако большого количества достоверных различий между результатами, в том числе для мальчиков и девочек, не обнаружено. Выявлено комплексное воздействие избранного ритма на результативность бега спортсменов с нарушениями зрения. Обнаруженные реакции связаны с нозологическим особенностями участников исследования. Однако, необходимо проведение более глубоких исследований. На этом этапе мы склонны думать, что выбранные частоты метронома удобны для работы с нагрузкой, которая повышается ступенчато.
\end{abstract}

Ключевые слова: метроном, ритм, темп, легкая атлетика. 


\section{СЛОБОЖАНСЬКИЙ НАУКОВО-СПОРТИВНИЙ ВІСНИК}

Abstract. Andrii Yefremenko, Svyatoslav Koval, Viktor Pavlenko, Tetiana Shutieieva, Yaroslav Kraynik, Svetlana Pyatisotskaya. Audio stimulation athletes with visual impairments in running. Purpose: to reveal differences between the running characteristics of athletes with visual impairment without and with audio stimulation. Objects: athletes with visual impairments (category T13) (boys $n=6$ and girls $n=5$ ). Material and Methods: test №1: running for 4 minutes with a gradual increase in pace; test №2: running for 4 minutes in the tempo of the metronome (140; 150; 160; 170 bpm). Results: Comparison of test results №1 and №2 in the group of young men revealed the reliability of differences $(p<0,05)$ for: the first and fourth minutes of running; average running speed in the second minute. Comparison of the results of tests №1 and №2 in the group of girls revealed the reliability of differences $(p<0,05)$ for: the distance of running in the first minute; average running speed in the first and second minutes. Conclusions: similar physiological reactions were recorded in boys and girls on exercise, which increases in steps, regardless of the method of stimulation. At the same time, there are certain differences in the strategy of movement, depending on the method of stimulation. This confirms the complex effect of the imposed rhythm on the performance of cyclic locomotion. We expected significant differences between running characteristics with and without auditory stimulation. However, a large number of reliable differences between the results, including for boys and girls, were not found. At this stage, we are inclined to think that the selected metronome frequencies are convenient for running with a load that rises stepwise.

Keywords: metronome, rhythm, tempo, athletics.

\section{References}

1. Riadova, L., \& Shesterova, L. (2018), «Age dynamics of the level of development of static balance in middle school students with visual impairments», Slobozhanskyi naukovo-sportyvnyi visnyk. No.3(65). 52-56. (in Ukr.)

2. Bacon, C. J., Myers, T. R., Karageorghis, C. I. (2012), «Effect of music-movement synchrony on exercise oxygen consumption», J Sports Med Phys Fitness. No. 52. 359-365. (in Eng.).

3. Edworthy, J., Waring, H. (2006), «The effects of music tempo and loudness level on treadmill exercise», Ergonomics. No. 49. 1597-1610. (in Eng.).

4. Hoffmann, C. P., Torregrosa, G., Bardy, B. G. (2012), «Sound Stabilizes Locomotor-Respiratory Coupling and Reduces Energy Cost», PloS one. No. 7(9). URL: https://doi.org/10.1371/journal.pone.0045206 (in Eng.).

5. Hove, M. J., Risen J. L. (2009), «lt's all in the timing: Interpersonal synchrony increases affiliation”, Soc. Cogn. No. 27. 949961. (in Eng.).

6. Karageorghis, C. I., Terry, P. C., Lane, A. M., Bishop, D. T., Priest, D. L. (2012), «The BASES expert statement on use of music in exercise», J. Sports Sci. No.30. 953-956. (in Eng.).

7. Kyrulginen, H., Pullinen, T., Candau, R., Avela, J., Huttunen, P., Komi, P. V. (2000), «Effects of marathon running on running economy and kinematics», Eur. J. Appl Physiol. No. 82. 297-304. (in Eng.).

8. Mendonзa, C., Oliveira, M., Fontes, L., Santos, J. (2014), «The effect of instruction to synchronize over step frequency while walking with auditory cues on a treadmill», Hum Mov Sci. №33. 33-42. (in Eng.).

9. Place, N., Lepers, R., Deley, G., Millet, G. Y. (2004), «Time course of neuromuscular alterations during a prolonged running exercise», Med. Sci. Sports Exerc. No. 36. 1347-1356. (in Eng.).

10. Roerdink, M., Ridderikhoff, A., Peper, C. E., Beek, P. J. (2013), «Informational and neuromuscular contributions to anchoring in rhythmic wrist cycling», Ann Biomed Eng. No. 41. 1726-39. (in Eng.).

Received: 05.03.2021.

Published: 26.04.2021.

\section{Відомості про авторів / Information about the Authors}

Єфременко Андрій Миколайович: к. фіз.вих., доцент; Харківська державна академія фізичної кульутри: вул. Клочківська, 99, м. Харків, 61058, Україна.

Ефременко Андрей Николаевич: к. физ.восп., доцент; Харьковская государственная академия физической культуры: ул. Клочковская, 99, г.Харьков, 61058, Украина.

Andrii Yefremenko: PhD (Physical Education and Sport), Associate Professor; Kharkiv State Academy of Physical Culture: Klochkivskastreet 99, Kharkiv, 61058, Ukraine.

\section{ORCID: https://orcid.org/0000-0003-0924-0281}

E-mail: ukrnac@ukr.net

Коваль Святослав Святославович: к.фіз.вих., доцент; Харківська державна академія фізичної культури: вул. Клочківська 99, Харків, 61058, Україна.

Коваль Святослав Святославович: к.физ.восп., доцент; Харьковская государственная академия физической культуры: ул. Клочковская 99, г. Харьков, 61058, Украина.

Svyatoslav Koval: PhD (Physical Education and Sport), Associate Professor; Kharkiv State Academy of Physical Culture: Klochkivskastreet 99, Kharkiv, 61058, Ukraine.

ORCID: https://orcid.org/0000-0001-7140-6276

E-mail: Koval.S.S.79@gmail.ru

Павленко Віктор Олексійович: к.пед.наук, доцент; Харківська державна академія фізичної культури: вул. Клочківська 99, м. Харків, 61058, Україна.

Павленко Виктор Алексеевич: к.пед наук, доцент; Харьковская государственная академия физической культуры: ул. Клочковская 99, г. Харьков, 61058, Украина.

Viktor Pavlenko: PhD (Pedagogical Science), Associate Professor; Kharkiv State Academy of Physical Culture: Klochkivskastreet 99, Kharkiv, 61058, Ukraine.

ORCID: https://orcid.org/0000-0003-0888-2485

E-mail: pavlenko102@ukr.net 
Шутєєва Тетяна Миколаївна: Харківська державна академія фізичної культури: вул. Клочківська 99, м. Харків, 61058, україна.

Шутеева Татьяна Николаевна: Харьковская государственная академия физической культуры: ул. Клочковская 99, г. Харьков, 61058, Украина.

Tetiana Shutieieva: Kharkiv State Academy of Physical Culture: Klochkivska str. 99, Kharkiv, 61058, Ukraine.

ORCID: https://orcid.org/0000-0002-0217-9505

E-mail: polyna71@mail.ru

Крайник Ярослав Богданович: к.фіз.вих., Харківська державна академія фізичної культури: вул. Клочківська 99, м. Харків, 61058, Україна.

Крайник Ярослав Богданович: к.физ.восп.; Харьковская государственная академия физической культуры: ул. Клочковская 99, г. Харьков, 61058, Украина.

Yaroslav Kraynik: Kharkiv State Academy of Physical Culture: Klochkivskastreet 99, Kharkiv, 61058, Ukraine.

ORCID: https://orcid.org/0000-0003-1567-8570

E-mail: yaroslavkr2014@gmail.com

Пятисоцька Світлана Сергіївна: к.фіз.вих., доцент; Харківська державна академія фізичної культури: вул. Клочківська 99, м. Харків, 61058, Україна.

Пятисоцкая Светлана Сергеевна: к.физ.восп., доцент; Харьковская государственная академия физической культуры: ул. Клочковская 99, г. Харьков, 61058, Украина.

Svetlana Pyatisotskaya: PhD (Physical Education and Sport), Associate Professor; Kharkiv State Academy of Physical Culture: Klochkivska str. 99, Kharkiv, 61058, Ukraine.

ORCID: https://orcid.org/0000-0002-2246-1444

E-mail: skharchenko@rambler.ru 